\title{
On the Effect of the Extrusion Speed on Microstructure and Plastic Deformation of ZE10 and ZEK100 Magnesium Alloys - an Acoustic Emission Study
}

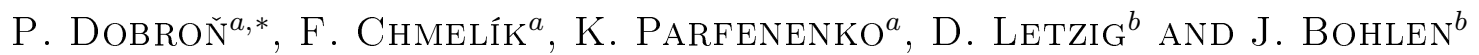 \\ ${ }^{a}$ Department of Physics of Materials, Charles University Prague, Ke Karlovu 5, 12116, Prague 2, Czech Republic \\ ${ }^{b}$ Helmholtz-Zentrum Geesthacht, Zentrum für Material- und Küstenforschung GmbH \\ Max-Planck-Str. 1, D21502 Geesthacht, Germany
}

\begin{abstract}
Mg-Zn-based alloys ZE10 and ZEK100 have been extruded at different speeds varying from $1 \mathrm{~m} / \mathrm{min}$ to $20 \mathrm{~m} / \mathrm{min}$. Specimens taken in the extrusion direction were uniaxially loaded in tension and compression at room temperature. The results are discussed using concurrent acoustic emission monitoring during mechanical testing and the acoustic emission signal analysis that correlates the microstructure and the stress-strain curves to the possible deformation mechanisms. In all tests, the acoustic emission response exhibited a large acoustic emission peak at the beginning of plastic deformation. A small local maximum on the onset of the acoustic emission activity was frequently observed, i.e. at very low stresses. For the alloys with bimodal grain structure tested in compression, an additional acoustic emission peak appeared at larger strains. This peculiar behavior can be explained by interplay of (10-12)-twinning and dislocation slip in samples with various grain size distributions.
\end{abstract}

PACS: 81.05.Bx, 81.20.Ev, 62.20.F-, 61.05.cp, 43.40.Le

\section{Introduction}

Extrusion is an established production method which offers the possibility to produce competitive wrought $\mathrm{Mg}$ (semi-)products for many weight-sensitive applications. Especially the indirect extrusion process is used due to the absence of friction between the billet surface and the container, which results in a more uniform metal flow, less power requirement, better section uniformity along the length and leads to an improvement of the surface quality in comparison to the direct extrusion process [1-3].

Extruded $\mathrm{Mg}$ alloys typically exhibit textures with a preferential orientation of the basal planes parallel to the extrusion direction. Thus, deformation twinning is favored if a compressive stress is applied along the extrusion direction [4]. Therefore, $\mathrm{Mg}$ alloys show anisotropic and asymmetric properties at the yield point in tension and compression [5].

The extrusion parameters, e.g. the extrusion speed, can significantly influence the development of microstructure (i.e. the grain size and grain size distribution) and, consequently, influence the mechanical properties of the resulting profile $[6,7]$.

The acoustic emission (AE) technique was used as an in situ method for sensitive detection of the transient

* corresponding author; e-mail: dobronp@karlov.mff.cuni.cz elastic waves generated within the material during deformation due to sudden localized structure changes such as dislocation motion and twinning. AE parameters can be used to analyze collective dynamic processes that play a role during the plastic deformation of $\mathrm{Mg}$ alloys [8].

In this study, the relation between microstructure and resulting deformation mechanisms during mechanical testing of indirectly extruded ZE10 and ZEK100 magnesium alloys was investigated. Extrusion speeds varying from $1 \mathrm{~m} / \mathrm{min}$ to $20 \mathrm{~m} / \mathrm{min}$ were used to prepare $\mathrm{Mg}$ alloys with different grain sizes. Microstructure and texture analysis was applied to characterize the grain size distribution of the studied alloys. The AE measurements were used in order to determine the onset of various deformation mechanisms and relate them to changes in the microstructure.

\section{Experimental procedure}

In the present study, ZE10 $(\mathrm{Mg}+1.3 \mathrm{wt} \% \mathrm{Zn}+$ $0.1 \mathrm{wt} \% \mathrm{Ce}$ ) and its modification with zirconium $\mathrm{ZEK}$ $100(\mathrm{Mg}+1.3 \mathrm{wt} \% \mathrm{Zn}+0.2 \mathrm{wt} \% \mathrm{Ce}+0.5 \mathrm{wt} \% \mathrm{Zr})$ magnesium alloy cast billets with average grain size of $449 \pm 26 \mu \mathrm{m}(\mathrm{ZE} 10)$ and $135 \pm 23 \mu \mathrm{m}$ (ZEK100) were indirectly extruded at three different speeds $(1 \mathrm{~m} / \mathrm{min}$, $10 \mathrm{~m} / \mathrm{min}$ and $20 \mathrm{~m} / \mathrm{min}$ ). Extrusion was carried out at $300{ }^{\circ} \mathrm{C}$ to produce a round bar with a diameter of $17 \mathrm{~mm}$ which corresponds to an extrusion ratio of 1:30. 
Tensile (diameter $6 \mathrm{~mm}$, gauge length $36 \mathrm{~mm}$ ) and compression (diameter $11 \mathrm{~mm}$, gauge length $16.5 \mathrm{~mm}$ ) specimens were machined from the round bar parallel to the extrusion direction. Deformation tests were performed with a universal testing machine $\mathrm{Zwick}^{\circledR} \mathrm{Z}$ Z0 at room temperature and a constant strain rate of $10^{-3} \mathrm{~s}^{-1}$.

The computer-controlled DAKEL-XEDO-3 system was used to monitor $\mathrm{AE}$ on the basis of a threshold level detection, which yields a comprehensive set of AE parameters involving count rate $N_{\mathrm{C}}$ (count number per second [9]) at defined threshold level. More details on the setup are reported in [10].

A Panalytical X-ray diffractometer setup using $\mathrm{Cu} K_{\alpha}$ radiation was employed to measure pole figures on polished samples in reflection geometry to a sample tilt of $70^{\circ}$. The $(0002),(10 \overline{1} 0),(10 \overline{1} 1),(11 \overline{2} 0)$, and (10 $\left.\overline{1} 3\right)$ pole figures were measured and used to calculate the complete orientation distribution which allows for the recalculation of full pole figures.

\section{Experimental results}

Micrographs of extruded alloys are presented in Fig. 1. Both alloys extruded at $1 \mathrm{~m} / \mathrm{min}$ exhibit an inhomogeneous microstructure consisting of large unrecrystallized grains and newly formed smaller grains due to recrystallization. The other extrusion speeds resulted in almost recrystallized microstructure, whereby the grain size is significantly lower in the Zr containing ZEK100 alloy than in the $\mathrm{Zr}$ free ZE10. The dependence of the average grain size on the extrusion speed can be found in Fig. 2 . In the case of ZE10, the average grain size increases with increasing extrusion speed. A different dependence can be seen in ZEK100 where after using extrusion speeds of 10 and $20 \mathrm{~m} / \mathrm{min}$ no changes in the grain size are observed.

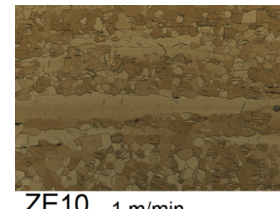

ZE10 $1 \mathrm{~m} / \mathrm{min}$

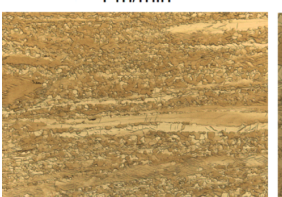

ZEK100

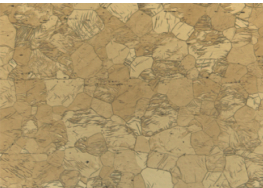

$10 \mathrm{~m} / \mathrm{min}$
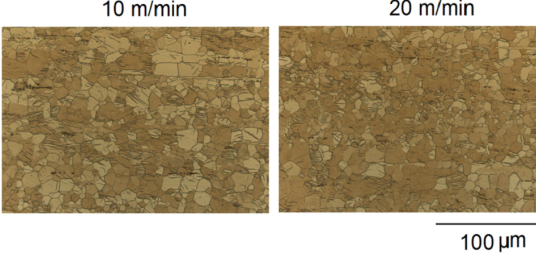

Fig. 1. Micrographs of extruded alloys.

The distribution of basal orientations (0002) is depicted in Fig. 3. A strong texture with the (0002) basal planes preferentially parallel $\left(\psi=90^{\circ}\right)$ to the extrusion axis was observed in all samples, especially in those extruded at $1 \mathrm{~m} / \mathrm{min}$. The increase in the extrusion speed leads to a distinct decrease of the texture strength, i.e.

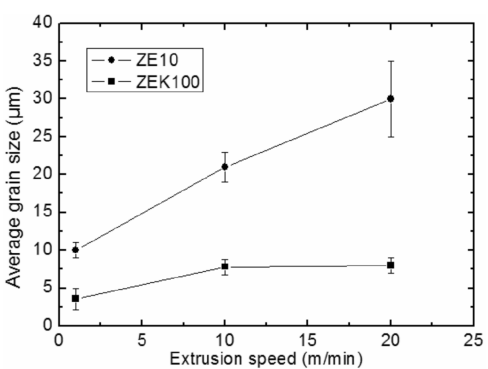

Fig. 2. Average grain size vs. extrusion speed for both alloys.

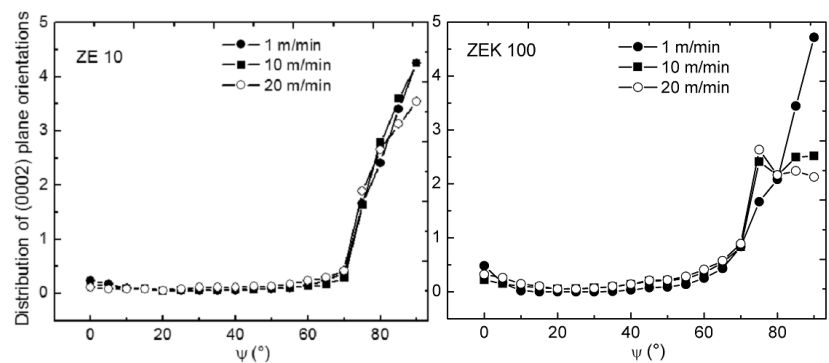

Fig. 3. The distribution of basal (0002) plane orientations as a function of the angle $\psi$ (angle between extrusion direction and normal vector of basal plane).

the number of basal (0002) planes with the orientation of $\psi=80-90^{\circ}$ slightly decreases. In the case of ZEK100, a preferential orientation of basal planes with $\psi$ about $70-80^{\circ}$ developed during extrusion at 10 and $20 \mathrm{~m} / \mathrm{min}$.

The shape of the tension and compression stress-strain curves is typical for extruded $\mathrm{Mg}$ alloys and characteristic parameters of deformation tests are presented in Table. A strong tension-compression asymmetry in the yield strength (YS) and a small yield point (YP) in compression test were found. The concurrent AE count rate is measured per time unit and related to the corresponding strain via the constant strain rate.

In the tensile test (Fig. 4), the AE activity increases with increasing extrusion speed and it is much higher in ZE10 than in ZEK100. Furthermore, the AE count rate exhibits a peak at the onset of plastic deformation in all samples and the subsequent decrease in the AE activity is more pronounced in ZEK100 than in ZE10.

In the compression test (Fig. 5), an AE peak at the macroscopic yield point with following decrease of the AE activity was also observed. However, this peak is more pronounced if compared to the one in the tensile test. The AE count rate, observed in both alloys extruded at $1 \mathrm{~m} / \mathrm{min}$, shows a second strong peak occurring after the YP.

\section{Discussion}

It was reported in [11-13] that $\mathrm{Zr}$ is a potent grain refiner in $\mathrm{Al}$-free $\mathrm{Mg}$ alloys and therefore the lower grain 

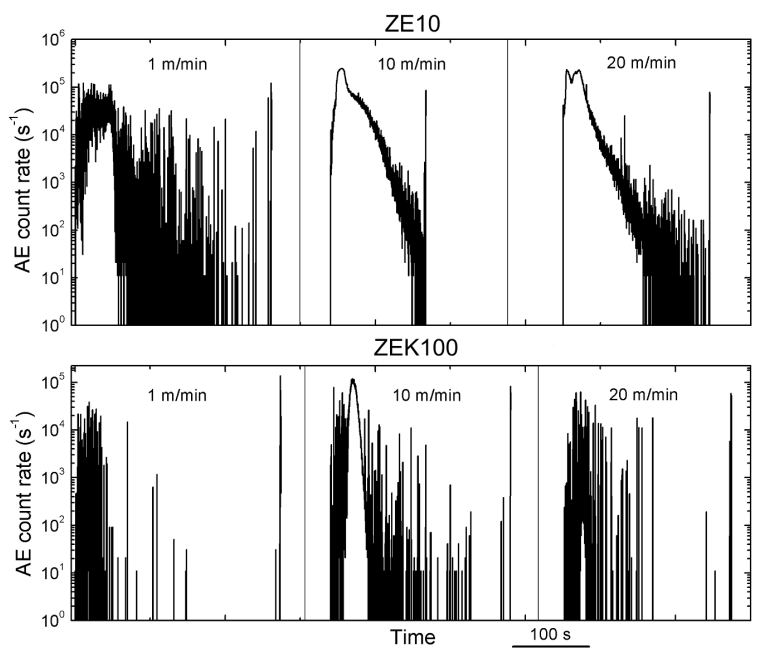

Fig. 4. AE count rate vs. time for both alloys at three extrusion speeds; tensile test.
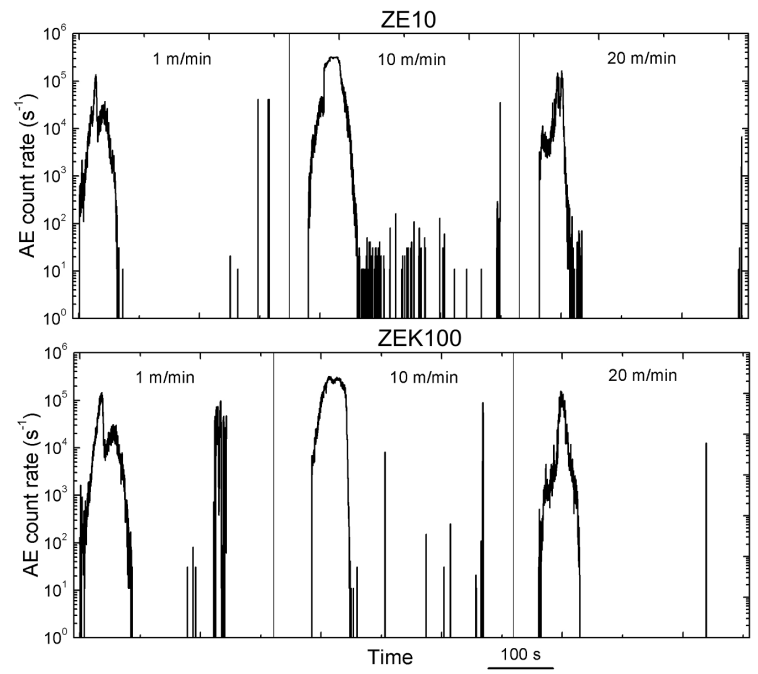

Fig. 5. AE count rate vs. time for both alloys at three extrusion speeds; compression test.

size in fully recrystallized ZEK100 by comparing to ZE10 could be attributed to $\mathrm{Zr}$ presence in the alloy.

An increase of the average grain size in ZE10, extruded at 1 and $10 \mathrm{~m} / \mathrm{min}$, does not lead to a significant change in the preferential orientation of basal planes (parallel to the extrusion direction). Unlike this, for ZEK100, weakening of the texture occurs, if the same experiments are compared. For a further increase of extrusion speed, a texture weakening corresponds to the ongoing increase of the average grain size in the case of ZE10. For the ZEK100, the off basal character of the texture strengthens without changes of the grain structure.

Results of deformation tests are consistent with microstructural observations. Higher stress values in
ZEK100 than in ZE10 can be explained by the finer grain structure according to the Hall-Petch relationship $[14,15]$. In the same way the decrease in stress with increasing extrusion speed can be understood. A large tension-compression asymmetry in the YS is a result of the strong extrusion texture where the occurrence of deformation $\{10-12\}\langle 10-1-1\rangle$ twins, if a compressive stress is applied along the extrusion direction, is responsible for low stress values. Thus the AE count rate during the tensile test can mainly be ascribed to collective dislocation processes. The characteristic AE peak at the onset of plastic deformation is usually explained by a massive dislocation multiplication where basal and non-basal slip systems and twinning (if present) are activated. The subsequent decrease in the $\mathrm{AE}$ count rate can be assumed to be a consequence of an increasing number of sessile dislocations reducing the free path of moving dislocations. The grain size effect on the $\mathrm{AE}$ activity, where the $\mathrm{AE}$ count rate decreases with decreasing average grain size, can be explained in a similar way as grain boundaries are also obstacles for dislocation motion. Therefore, in fine grained ZEK100, compared to ZE10, lower AE activity was observed. Obviously, the differences in the grain structure are consistent with the $\mathrm{AE}$ activity whereas the changes in the texture do not seem to influence the main deformation mechanisms.

In the compression test, twinning activation as an excellent source of the $\mathrm{AE}[16]$ is responsible for a strong $\mathrm{AE}$ activity. Two AE peaks observed in both alloys extruded at $1 \mathrm{~m} /$ min indicates an inhomogeneous microstructure with a broad grain size distribution. Dobron et al. [17] explained this behavior, observed in AZ31, by a dependence of twinning activation on the grain size where (10-12) twinning is first favored in the larger grains and as plastic deformation proceeds, it occurs also in the smaller grains. In fully recrystallized and homogeneous microstructure (with narrow distribution of grain size) of both alloys extruded at 10 and $20 \mathrm{~m} / \mathrm{min}$, the $\mathrm{AE}$ count rate shows only one broad peak. Furthermore, the high sensitivity of $\mathrm{AE}$ on even slight changes in the twinning activity [17] allows for a more detailed consideration of the twinning activity in compression. An increase of the AE peak intensity for the extrudates after 1 and $10 \mathrm{~m} / \mathrm{min}$ is consistent with the increase of the average grain size of both alloys whereas the decrease of the $\mathrm{AE}$ peak intensity with increasing extrusion speed to $20 \mathrm{~m} / \mathrm{min}$ is not. However, a decrease of the preferential orientation of basal planes parallel to the extrusion direction can lead to preferred basal slip and reduced twinning activity. The following absence of $\mathrm{AE}$ indicates on intensive strain hardening and a saturation of the twin number. It was reported in $[18,19]$ that twin growth does not produce AE contrary to the twin nucleation. Correspondingly, in both alloys, new twins are formed ones at the beginning of plastic deformation (below 4\%) and at higher strains growth of already created twins occurs. 
Mechanical properties of extruded alloys: TYS - tensile yield strength, CYS - compressive yield strength, UTS - ultimate tensile strength, UCS - ultimate compressive strength.

\begin{tabular}{|c|c|c|c|c|c|c|c|c|c|}
\hline \multirow[t]{2}{*}{ Alloy } & \multirow{2}{*}{$\begin{array}{c}\text { Extrusion } \\
\text { speed } \\
{[\mathrm{m} / \mathrm{min}]} \\
\end{array}$} & \multicolumn{4}{|c|}{ Tensile test } & \multicolumn{4}{|c|}{ Compression test } \\
\hline & & $\begin{array}{c}\text { TYS } \\
{[\mathrm{MPa}]}\end{array}$ & $\begin{array}{c}\text { UTS } \\
{[\mathrm{MPa}]}\end{array}$ & $\begin{array}{c}\text { Uniform } \\
\text { elongation [\%] }\end{array}$ & $\begin{array}{c}\text { Fracture } \\
\text { strain }[\%]\end{array}$ & $\begin{array}{l}\text { CYS } \\
{[\mathrm{MPa}]}\end{array}$ & $\begin{array}{c}\text { UCS } \\
{[\mathrm{MPa}]}\end{array}$ & $\begin{array}{c}\text { Uniform } \\
\text { elongation [\%] }\end{array}$ & $\begin{array}{l}\text { Fracture } \\
\text { strain [\%] }\end{array}$ \\
\hline ZE10 & 1 & $206( \pm 1)$ & $261( \pm 3)$ & $10.3( \pm 0.1)$ & $20.1( \pm 0.4)$ & $124( \pm 2)$ & $410( \pm 7)$ & $9.6( \pm 0.3)$ & $10.0( \pm 0.3)$ \\
\hline ZE10 & 10 & $176( \pm 2)$ & $245( \pm 2)$ & $6.6( \pm 0.3)$ & $11.7( \pm 2.5)$ & $81( \pm 1)$ & $361( \pm 4)$ & $9.9( \pm 0.4)$ & $10.5( \pm 0.5)$ \\
\hline ZE10 & 20 & $156( \pm 2)$ & $226( \pm 2)$ & $7.8( \pm 0.3)$ & $18.1( \pm 1.3)$ & $70( \pm 1)$ & $347( \pm 1)$ & $10.2( \pm 0.4)$ & $11.3( \pm 0.6)$ \\
\hline ZEK100 & 1 & $305( \pm 3)$ & $313( \pm 3)$ & $7.5( \pm 0.1)$ & $21.0( \pm 4.0)$ & $173( \pm 1)$ & $436( \pm 15)$ & $7.6( \pm 0.3)$ & $7.6( \pm 0.3)$ \\
\hline ZEK100 & 10 & $204( \pm 1)$ & $257( \pm 1)$ & $9.3( \pm 0.1)$ & $20.3( \pm 0.9)$ & $126( \pm 4)$ & $384( \pm 13)$ & $9.1( \pm 0.3)$ & $9.9( \pm 0.4)$ \\
\hline ZEK100 & 20 & $209( \pm 2)$ & $259( \pm 2)$ & $9.2( \pm 0.1)$ & $22.6( \pm 0.5)$ & $124( \pm 1)$ & $375( \pm 3)$ & $8.7( \pm 0.1)$ & $9.5( \pm 0.1)$ \\
\hline
\end{tabular}

\section{Conclusions}

The extrusion speed variation leads to considerable changes in the microstructure of both ZE10 and ZEK100 alloys. With increasing extrusion speeds the microstructure is almost recrystallized and becomes more homogeneous without any significant changes in the texture. In the ZEK100 alloy, the presence of $\mathrm{Zr}$ contributes to the stabilization of the alloy microstructure, which could be of application interests. The AE measurements show the onset of the activation of deformation mechanisms in both tension and compression mode and underline twinning activation dependence on the grain size and texture.

\section{Acknowledgments}

This work received support from the Czech Science Foundation under grant P108/10/P430 and additional support was provided by the Research Project 1 M 0556 "Eco-centre for Applied Research of Non-ferrous Metals" financed by the Ministry of Education, Youth and Sports of the Czech Republic. K.P. is grateful for financial support from the Grant Agency of Charles University No. 166310 and also for the grant SVV-2011-263303, and F.C. is grateful to the Alexander von Humboldt Stiftung for financial support during his stay in Germany.

\section{References}

[1] K.U. Kainer, E. Doege, S. Janssen, T. Ebert, in: Magnesium Alloys and Their Applications, Ed. K.U. Kainer, Wiley-VCH, Weinheim 2000, p. 596.

[2] W.H. Sillekens, J.A.F.M. Schade, van Westrum, A.J. den Bakker, P.J. Vet, Mater. Sci. Forum 426-432, 629 (2003).

[3] K.B. Müller, in: Annual Meeting on Magnesium Technology, Seattle 2002, Ed. H.I. Kaplan, The Minerals, Metals \& Materials Society (TMS), Warrendale 2002, p. 187.
[4] D.W. Brown, S.R. Agnew, M.A.M. Bourke, T.M. Holden, S.C. Vogel, C.N. Tomé, Mater. Sci. Eng. A 399, 1 (2005).

[5] J. Bohlen, P. Dobroň, J. Swiostek, D. Letzig, F. Chmelík, P. Lukáč, K.U. Kainer, Mater. Sci. Eng. A 462, 302 (2007).

[6] J. Bohlen, S. Yi, D. Letzig, K.U. Kainer, Mater. Sci. Eng. A 527, 7092 (2011).

[7] G. Mann, J.R. Griffiths, C.H. Cáceres, J. Alloys Comp. 378, 188 (2004).

[8] P. Dobroň, F. Chmelík, J. Bohlen, K. Hantzsche, D. Letzig, K.U. Kainer, Int. J. Mater. Res. 6, 888 (2009).

[9] Standard Practice for Acoustic Emission Examination of Fiberglass Reinforced Plastic Resin, ASTM E 1067-85, Tank/Vessels, May 31 (1985).

[10] J. Bohlen, F. Chmelík, P. Dobroň, D. Letzig, F. Kaiser, P. Lukáč, K.U. Kainer, J. Alloy Comp. 378, 214 (2004).

[11] H. Okamoto, J. Phase Equilibria 23, 198 (2002).

[12] D.H. StJohn, M. Qian, M.A. Easton, P. Cao, Z. Hildebrand, Metall. Mater. Trans A 36, 1669 (2005).

[13] M. Qian, A. Das, Scr. Mater. 54, 881 (2006).

[14] E.O. Hall, Proc. Phys. Soc. B 64, 747 (1951).

[15] N.J. Petch, J. Iron Steel Institute, 25 (1953).

[16] C.R. Heiple, S.H. Carpenter, J. Acoust. Emission 6, 177 (1987).

[17] P. Dobroň, F. Chmelík, S. Yi, K. Parfenenko, D. Letzig, J. Bohlen, Scr. Mater. 65, 424 (2011).

[18] J.P. Toronchuk, Mater. Eval. 51 (1977).

[19] C.R. Heiple, S.H. Carpenter, J. Acoust. Emission 6, 215 (1987). 